\title{
Entre Sciarrino e Berio, entre modo e maneira
}

\section{Leonardo Aldrovandi}

(Universidade Anhembi Morumbi)

Resumo: Este trabalho se vale de alguns conceitos da história da arte para refletir sobre uma diferença geral e de ordem estética entre dois dos compositores italianos mais expressivos das últimas décadas, Luciano Berio e Salvatore Sciarrino. Ainda que a distinção entre o maneirismo da estética de Berio e o naturalismo de Sciarrino seja aqui apenas metodológica, há entre ambos um sentido bem diferenciado da experiência musical sobre o qual esta distinção fornece pistas. O método por comparação global esboçado, inclusive ao remeter anacronicamente a Giotto, Leonardo, Michelangelo, dentre outros, é um instrumento de diferenciação reflexiva, entre muitos possíveis.

Palavras-chave: estética, naturalismo, maneirismo, composição, Itália.

\section{MANNER AND MODE IN SCIARRINO AND BERIO}

Abstract: This paper discusses a broader aesthetical difference in the work of two of the most prominent Italian composers of the last few decades, using a comparative method based on some concepts drawn from the history of Italian art, such as, mannerism, naturalism, transcendence, immanence, among others. Such method by comparison, evoking as well known figures from the arts such as Giotto, Leonardo and Michelangelo, is a tool that may offer some clues to the comprehension of aesthetic differentiation in music.

Keywords: Aesthetics, naturalism, mannerism, composition, Italy. 


\section{Naturalismo e maneirismo}

Em meio a seu arsenal teórico tão questionado, o artista e historiador Vasari fez uma distinção bastante clara e conhecida entre maneirismo e naturalismo no século XVI. Maneirismo, para ele, é simplesmente a arte de imitar a arte e não a natureza. Seguindo tal distinção, o historiador Giulio Carlo Argan", também bastante questionado, argumenta que Michelangelo, Rafael ou Bramante, por exemplo, teriam tornado suas atividades independentes da tentativa de expressar a realidade objetiva, ao visar exprimir uma ideia que o artista teria em mente. Elas formariam, assim, uma arte mais voltada para o sujeito, para a religiosidade, para a transcendência, do que para o objeto, para o olhar objetivo ou para a natureza.

Neste contexto teórico generalizante, uma das grandes premissas de um maneirista seria a de buscar perturbar uma matéria ou um material com o objetivo de liberar o desenho, o traçado, o contorno, o gesto. As mãos, não os modelos, são operatórias. Ora, esta consideração pode ganhar, como tantas outras da discussão sobre a pintura, aplicação ao nosso terreno da música. No terreno musical de hoje, toda discussão um tanto acinzentada sobre a relação entre gesto, figura e textura, deveria considerar o que, na pintura, já é discutido há séculos com mais cores de pensamento. Por mais que categorias como naturalismo e maneirismo sejam generalizações muitas vezes questionáveis, elas nos ajudam a ter um olhar panorâmico mais claro sobre a estética de diferentes compositores.

Luciano Berio, por exemplo, talvez não quisesse, de uma forma totalmente programada, "perturbar" o material musical ou sonoro. No entanto, certamente podemos sentir sua busca pela liberação do desenho musical ao longo da forma das peças. Ao falar em desenho, podemos dizer que é do contorno e da

\footnotetext{
1 Temos consciência do anacronismo das comparações deste texto e sobre autores envolvidos. Mas muitas vezes é preciso considerar este que é o maior dos pecados para os historiadores de outra forma. Evidentemente, não estamos preocupados com esta fidelidade contextual, detalhista ou histórica, sendo o método por comparação apenas um instrumento para pensar uma diferença artística genérica e sensível na escuta e na experiência global das obras. Podemos dizer, com Olivier Dumoulin, que este mesmo pecado original também pode ser fonte do conhecimento (Dumoulin, 1986).
} 
tensão das linhas e das estruturas expressas dentro de uma condução formal mais global que estamos tratando. Como em Michelangelo, o trabalho sobre as tensões e ímpetos dos gestos tornam forças dramáticas constantemente tangíveis, sensíveis. E é a forma como o gesto é liberado por um desenho figural ou por um contexto textural o que o torna o principal instrumento da expressão. Gesto que nunca é um jogo, mas parte de um.

Em Berio, como em Michelangelo, não existe o dilema entre cheio e vazio e as formas são mais desenhadas do que modeladas. A sensação de movimento está mais na transcendência dos corpos e das linhas (sonoros, humanos, visuais, não importa). Como Michelangelo, Berio pinta a cultura, o homem. Mas o homem que se esforça ou encena sua saída das pedras e faz desta gestualidade, heroica ou não, dramática, mas não tão trágica, a cena da sua própria expressão. Não é à toa que todo seu referencial antropológico e literário, mesmo que dominante naquelas décadas, sempre esteve mais próximo de ideias em torno da cultura, da estrutura e da linguagem, do que de modelos naturais de observação.

Se nos for permitido aproximar, grosseiramente, Berio a Michelangelo, podemos então dar continuidade a nosso exercício anacrônico ao aproximar Sciarrino de outros artistas. Argan argumenta algo próximo ao seguinte: em Leonardo, é a experiência da natureza que o faz expressar uma batalha por meio de ciclones, vórtices de fumaça, ventos, em suma, um furor igual para homens, cavalos, plantas e tormentas. Ao contrário de uma batalha pintada por Michelangelo, o homem, ali, é apenas mais um dentro de uma amplidão natural. Ora, isto se aproxima da estética de Sciarrino. Assim como em grande parte de sua obra mais tardia, a sensação de movimento está mais na imanência dos traços e dos corpos dentro de uma globalidade descomunal, praticamente impensável como totalidade, uma espécie de abertura espacial ilimitada. A realidade é esta imensidão e só podemos colhê-la através de fenômenos particulares. Estes fenômenos, pequeninos perto da globalidade inalcançável, ganham força na sua própria compacidade. Aqui sim, a dialética do cheio e do vazio ganha peso ontológico e espiritual. "O silêncio é um muro com fissuras", diz seu madrigal. Podemos senti-lo desta forma em muitas de suas composições. Mas é importante distinguir seu silêncio do silêncio transcendental de um John Cage, por exemplo. 0 
silêncio de Sciarrino é fabricado a partir do comportamento e da característica da materialidade sonora, sentido através da sua efemeridade, localidade, compacidade repetitiva, envolta de pausas precisas, em geral meticulosamente calculadas. Ou seja, ele é edificado. Ele não está baseado na abertura do sentido a um acontecimento mais puro ou assim idealizado. Daí encontrarmos nele uma relação maior com a pintura naturalista do que com o próprio meio ambiente. Mais ainda com a pintura do século XVI para trás, especialmente a partir de Giotto, se quisermos, já que estéticas naturalistas como as do romantismo não se aproximam disto por uma série de motivos. Sem entrar muito no mérito, podemos dar apenas um exemplo de argumento: não existe uma linguagem oculta da natureza para Sciarrino como existe para grande parte dos românticos. O naturalismo tem outra característica. O significado transcendente deste espaço ilimitado é totalmente audível, presente. E, como em Giotto, podemos sentir a gravidade transcendental de um espaço que nunca será ultrapassado, nem mesmo pelo gesto mais divino de um São Francisco.

Considerando um pouco de tudo isto, vale colocarmos mais uma tese de Argan que nos servirá de instrumento: para Leonardo, a arte é a pesquisa do valor da experiência que se faz do fenômeno, e este vale quando, no particular, manifesta a globalidade do real. Se em Sciarrino, a realidade não é uma questão, o modelo natural intransponível certamente o é. O naturalismo tende sempre ao observado, ao objeto como foco mimético e ao modelo: o vôo de um passarinho, o pio de uma coruja, mas também, a forma de agrupamento dos elementos de um fenômeno, formação, deformação etc. No caso de Sciarrino, procurar ser realista não é, evidentemente, a grande questão mimética. Antes, é dotar de verdade a atividade artística com procedimentos de organização que, por mais abstratos ou humanos que sejam, sempre serão encontrados no comportamento de naturezas particulares. Quando Sciarrino diz que somos naturalistas mesmo quando não queremos, um pouco disto é o que está em jogo. Algo de inquestionável ou de inevitável a respeito da relação com as naturezas. É assim que ele busca demonstrar como, numa obra tão mental e supostamente maneirista como Kontrapunkte, de Stockhausen, podemos encontrar modelos naturais em seu fundamento. 


\section{Usos da figuração}

Tomando o naturalismo como base de ação da arte, podemos notar que seu uso, em Sciarrino, é comparável ao que ocorre na oscilação quase inescapável, como no século XVI, dos fundamentos miméticos em modelos naturais: este movimento pendular de um modelo como realidade incontornável, quase como uma verdade de fundamento, e um procedimento abstrato, mental, aceito, recusado ou interpretado. Pois se, por um lado, Sciarrino fala de uma inevitabilidade do naturalismo, por outro, mostra que seus procedimentos figurais são abstrações sensíveis ou texturais conceituadas (little big-bang, multiplicação, acumulação etc), os quais podem ou não ser tomados como realidade na música. Estas são as figuras para ele, ou seja, os próprios procedimentos que espelham uma sensação emergente das diferentes formas de agrupar os sons.

Podemos sentir como a comparação com os pintores tem o seu limite. Mas muitas analogias são válidas. Neste Sciarrino de que falamos, como na pintura de um Lorenzetti ou mesmo de um Carpaccio, todo pequeno elemento é valorizado no processo de formação de cada espaço compositivo ou figura global. Qualquer suposto cenário (scance-frons) tem o mesmo peso de sensação que figuras maiores, mais frontais ou mais impactantes. Há uma sensibilidade para a pintura do espaço compositivo que dá valor a cada pequena forma por suas cores, caracteres, formas e tamanhos bem diferenciados.

Já em Berio, como em Michelangelo ou Simone Martini, a expressão das figuras e seus choques geralmente acabam se tornando mais importantes que este campo de forças estável do espaço compositivo. Aqui existe uma diferença de sensação ainda mais básica que convém esboçar: aquela entre sentir o ser de um evento num mundo e o ser que busca transcender seu mundo. Estas são duas filosofias diferentes em relação ao uso das figuras. Uma caracteriza a textura por procedimentos típicos (no caso de Sciarrino, multiplicação, acumulação, transformação genética, little big-bang etc), e a outra a desenvolve por operações de variação, projeção, extratificação dimensional de gestos e linhas caracterizados (por exemplo, anamorfismo em Sciarrino, ampliação das figuras circulares em Berio). Vemos aí como nossas aproximações são relativas. Sciarrino é mais 
maneirista quando se vale de técnicas anamórficas. Mas nas suas várias figuras tipológicas, seu naturalismo é bem evidente e a imanência dos gestos estabiliza a caracterização da textura pela figura. No outro caso, tendência em Berio, é a mutabilidade do gesto, a variabilidade de suas figurações e desfigurações, a representação de sua transcendência mesma, o que dimensiona a textura e a própria forma.

É claro que o escoamento formal existe em ambos os casos, embora suas estratégias variem em função destas filosofias diferentes (modelagem e desenvolvimento). Dizendo ainda de outra maneira, num caso, a figura caracteriza a textura por tipos conceituados de agrupamento de elementos baseados em modelos de comportamento, e no outro, as operações figurais desenvolvem e transformam a textura e os gestos (sobreposição variável de planos temporais, projeções por desenhos de circularidade variáveis, jogos no âmbito de alturas, filtragem, séries defectivas, desviantes, derivações, processos de bricolagem etc).

Daí a experiência da repetição em Berio ser geralmente mais camuflada pela variação mais frequente de elementos sobrepostos que se interpenetram. Em Sciarrino, muitas vezes há uma dimensão quase banal da repetição. No entanto, ela está ligada a uma projeção formal e qualitativa (tímbrica) bastante cuidadosa disto que chamamos de espaço compositivo. Ela opera como agente de sensação de um mundo dado e não feito para ser ultrapassado. Tanto a forma como as qualidades sensíveis dos objetos compostos são pensados de modo a fazer da repetição banal uma força de expressão e estabilização deste espaço, não uma previsibilidade estanque. Muitos dos que criticam a simplificação de suas texturas geralmente não atentam para o grande arco formal e espiritual que ordena suas peças em função da sensação de um espaço (e não gesto) transcendente. Podemos até especular um pouco mais: talvez, mais do que falar em animismo, este tipo de experiência de escuta pode nos levar mais ao conceito hoje celebrado de multinaturalismo. Numa visão multi-naturalista, podemos dizer que tudo é cultura, ou seja, espírito, mesmo aquilo que tratamos como natureza. Já a natureza não é única, é plural em seus corpos tão variados ${ }^{2}$. Pensemos na textura mais típica de

\footnotetext{
${ }^{2}$ Ver Viveiros de Castro, Eduardo (2002)
} 
Sciarrino. Uma natureza plural de corpos particulares, localizados e diferentes, e um “espírito” global comum a todos, aqui representado por este espaço ilimitado, delineado pelo silêncio como fio ou elo de escuta da forma. Em suma, agradando ou não aos ouvintes, é importante destacar um lado mais incomum para este tipo de escuta. Daí um cuidado necessário de não tratar a ausência de uma trama mais dramática sobre os sons, ou a ausência de alguma busca transcendental dos gestos ou do homem, como uma ausência de expressão, dada uma tendência mais ocidental em identificar um fio dramático com a realidade de uma expressão.

\section{Anacronicamente viável}

Sabemos que o uso de materiais antigos ou catalogados é comum a ambos autores, como é o caso aliás de muitos artistas italianos. Isto não é resultado, simplesmente, do gosto pessoal dos compositores, pois, no caso da Itália, há um traço importante: a cultura italiana nasceu positivamente anacrônica ${ }^{3}$. Ao observar a história da arte italiana e da sua literatura, esta ideia de resgate de materiais tornou-se uma constante ao longo dos séculos. Só que as formas de sentir, pensar e utilizar estes materiais do passado são, evidentemente, bem distintas em cada autor e em cada obra.

Em Berio, o uso de materiais culturalmente estabelecidos costuma visar também uma espécie de culturalismo. Sua ligação quase imediata a uma ideia de gesto se deve em grande parte a uma tentativa vaga e global do compositor de apropriação de um conceito brechtiano. Pois, como bem demonstra OsmondSmith, nem todo gesto na música de Berio equivale ao Gestus brechtiano, já que este nem sempre é físico e sempre depende de uma característica culturalmente estabelecida que é expressa em função de uma estrutura dramatúrgica ${ }^{4}$. Mas por que falamos em culturalismo? O uso de materiais estilizados não é somente um jogo composicional com significados culturais convencionais diversos, mas uma operação que busca demonstrar, ironicamente ou não, alguma condição de

\footnotetext{
${ }^{3}$ Ver Sterzi (2008)

${ }^{4}$ Osmond-Smith (2007), pp. 6-7.
} 
transcendência para eles, dando-Ihes um novo uso ou lugar, por estratégias de bricolagem, contextualização e transformação das sonoridades.

Em Sciarrino, a tradição ou o anacronismo é mais uma fonte de ideias e procedimentos do que uma espécie de conteúdo arlequinal. O material ou procedimento do passado se torna mais um modelo de organização de elementos ou método formal do que material estilístico significativo para um grande retraço ou desenho. Vale notar a importância da mão neste último caso, em relação ao tipo de mimese: a maneira, em contraposição ao modo, a manobra, em contraposição ao modelo.

É evidente que este tipo de discussão não tem fim. Vale lembrar que estas argumentações se referem ao que é dominante na obra destes autores e não constante. Há casos, por exemplo, onde um espaço compositivo se estabiliza em Berio, outros onde ele dá lugar a um fluxo mais dramático em Sciarrino. Estas comparações sempre vão carregar o limite teórico que as define.

\section{REFERÊNCIAS}

ARGAN, Giulio Carlo. Storia dell'arte italiana. Florença: Sansoni, 2002.

BERIO, Luciano. Poesia e musica - un'esperienza, Incontri Musicali, 3: 98-111. 1959.

. Du geste et de Piazza Carità. Paris: Contrechamps, 1, 1983.

DUMOULIN, Olivier. Anachronisme. Dictionnaire des sciences historiques. Paris: Presses Universitaires de France, 1986, p. 34.

OSMOND-SMITH, David. Introduction. Berio's Sequenzas. Burlington, VT: Ashgate, 2007, pp. 6-7.

SCIARRINO, Salvatore. Di una musica d'oggi. Firenze: Olschki, 1979. . L'immagine del suono. Grafici 1966-1985. ?: Latina, 1985 . La figura della musica, da Beethoven a oggi. Milão: Rircordi, 1998. . Carte da Suono. Roma: Cidim-Novecento, 2001.

STERZI, Eduardo. Por que ler Dante? Rio de Janeiro: Globo, 2008.

VIVEIROS de Castro, Eduardo. A inconstância da alma selvagem. São Paulo: Cosac $\&$ Naify, 2002. 